\title{
Fully Developed Compartment Fires: The Effect of Thermal Inertia of Bounding Walls on the Thermal Exposure
}

\author{
B. BФHM \\ Laboratory of Heating and Air Conditioning \\ Technical University of Denmark \\ Building 402A, DK-2800 Lyngby, Denmark
}

\section{ABSTRACT}

Based on an energy balance for the compartment gases the thermal exposure in fully developed fires is determined as a function of opening factor, fuel load and thermal inertia of the bounding walls. A conversion factor is calculated which makes it possible to carry out all calculations in a standard compartment by applying an equivalent fuel load and an equivalent opening factor. The conversion factor is determined as the thermal inertia in the standard compartment divided by the thermal inertia in the real compartment. The errors from this approximate method are estimated from the maximum steel temperatures of an unprotected and a protected steel structure placed inside the standard compartment and the real compartment. Nine different compartments are used and apart from the compartment made of steel the greatest error is smaller than 13\%. The normalized heat load concept introduced by Harmathy (7) is used as a principle of equivalent fire duration in the fire test furnace, in the standard compartment and in a compartment with low thermal inertia. The accuracy of the concept is estimated from the maximum steel temperature of a protected structure.

\section{Keywords}

Fully developed compartment fires, thermal exposure, thermal inertia, normalized heat load, equivalent fire duration, steel structures.

\section{INTRODUCTION}

For many years the fire resistance of building structures has been evaluated in fire test furnaces. The temperature-time curve which is followed in these tests is specified in standards, for instance ISO 834 .

Odeen (1) and Kawagoe (2) were among the first to calculate the thermal response of structures. An energy balance for the compartment gases became the basis for theoretical calculations of temperature-time curves in ventilation controlled fires. By computer simulations of a great number of fire tests Magnusson and Thelandersson (3) were able to specify the net energy release rate for the whole fire period and not only the fully developed period. Their model which is based on wood fires solely became the basis for differentiated design of steel structures, (4). For polyethylene fires a model was proposed by Bohm (5). When the energy release rate is prescribed 
in the models $(3,5)$ three main parameters determine the gas temperature-time curves: the opening factor $\mathrm{A} \sqrt{\mathrm{H}} / \mathrm{A}_{\mathrm{t}}$, the fuel load $\mathrm{E}$ and the thermal inertia $\sqrt{k \rho c}$ of the bounding walls.

The models assume a uniform compartment gas temperature although it is realized that temperature gradients will appear in real fires, (6). It should be remembered that the uncertainty associated with the thermal exposure in the compartment is superimposed on the uncertainty associated with the thermal and structural response of the structure itself.

The thermal inertia of the bounding walls influences the net heat flux to the walls and thereby the energy balance for the compartment gases. As a result gas temperature-time curves for design purposes will have to be calculated for a number of different bounding walls. To ease the application of these design curves for engineering purposes it would be helpful to restrict calculations to one type of compartment walls. An approximate method for "translation" of the thermal exposure in a specific compartment to that of a standard compartment is discussed in this paper.

The concept of normalized heat load introduced by Harmathy (7) is a measure of the destructive potential of a compartment fire. Compared with other principles of equivalent fire duration the importance of the normalized heat load concept is that it can be evaluated from the fire history and the fire compartment without knowledge of the actual structural element to be considered.

A comparison of the thermal response of structures exposed to either the standard fire curve ISO 834 or to the polyethylene design model will be reported here when the normalized heat load concept is applied as a principle of equivalent fire duration.

\section{THE CONVERSION FACTOR $k_{f}$}

pettersson et al. (4) introduced a standard compartment made of brick and concrete with thermal inertia $1168 \mathrm{~W} / \mathrm{s} / \mathrm{m}^{2} \mathrm{~K}$. The thermal exposure in other compartments is converted to the standard compartment by a conversion factor $k_{f}$. In the standard compartment (No. 1) an equivalent fuel load and an equivalent opening factor are applied:

equivalent fuel load $\quad=k_{E} \times$ true fuel load $\mathrm{E}$

equivalent opening factor $=\mathrm{k}_{\mathrm{f}} \times$ true opening factor $\mathrm{A} \sqrt{\mathrm{H}} / \mathrm{A}_{t}$

The conversion factor is independent of the magnitude of the fuel load, and not very dependent of the opening factor, (4). The conversion factors were found by direct comparison of the gas temperature-time curves in the different compartments.

From the compartment energy balance and with the bounding walls treated as semi-infinite solids it appears (8) that the conversion factor can be evaluated as

$\mathrm{k}_{\mathrm{f}}=\sqrt{\mathrm{k}_{\mathrm{NC}}} / \sqrt{\mathrm{k} \rho \mathrm{C}_{\text {true }}}$

where $\sqrt{\mathrm{k} \rho \mathrm{C}}$ is the thermal inertia of the bounding walls. 
In table 1 is shown the thermal inertia and the thermal conductivity of nine aifferent, homogeneous compartments. Also shown in the Table are conversion factors either from reference (4) or calculated according to equation (2).

For long fire durations the walls can no longer be treated as semiinfinite solids. The thermal penetration time has been discussed by Harmathy (9) and McCaffrey et al. (10) among others. Here the critical time when the temperature on the unexposed side of the wall starts to rise is calculated as:

$\tau_{\text {crit }}=0.05 \mathrm{~d}^{2} \frac{\rho \mathrm{c}}{\mathrm{k}}$

The critical time for $0.20 \mathrm{~m}$ wall thickness is shown in Table 1 . The material properties are evaluated at $700^{\circ} \mathrm{C}$.

It appears from Table 1 that the conversion factors given by pettersson et al. are somewhat closer to unity than the values obtained from the equation (2).

For thermally light walls with low thermal inertia the conversion factor will be greater than unity, and consequently the thermal exposure is expected to be greater than in the standard compartment.

\section{THERMAL EXPOSURE}

To characterize the thermal exposure in a specific compartment the following parameters will be calculated:

- maximum gas temperature

- the integral of the incident flux and of the net heat flux from the start of the fire to the end of the fully developed period $\tau$ *

- maximum steel temperature of two steel structures with surface area/volumeratio $100 \mathrm{~m}^{-1}$. One structure is unprotected, the other is protected with $20 \mathrm{~mm}$ rockwool insulation (material No. 7).

TABLE 1. Material properties for compartments 1-9, conversion factors and cxitical time $(0.20) \mathrm{m}$ wall thickness)

\begin{tabular}{|c|c|c|c|c|c|}
\hline \multirow{2}{*}{$\begin{array}{l}\text { Compartment number } \\
\text { and type }\end{array}$} & \multirow{2}{*}{$\begin{array}{l}\sqrt{\kappa \rho C} 700 \\
W \sqrt{s} / m^{2} \mathrm{~K}\end{array}$} & \multirow{2}{*}{$\begin{array}{r}k_{700} \\
w / \mathrm{m}^{\circ} \mathrm{C}\end{array}$} & \multicolumn{2}{|c|}{ Conversion factor $k_{f}$} & \multirow{2}{*}{$\begin{array}{c}{ }^{\top} \text { crit } \\
\text { minutes }\end{array}$} \\
\hline & & & $\operatorname{Ref}(4)$ & $1168 / \sqrt{\mathrm{k \rho c}}$ & \\
\hline 1 brick + concrete & 1168 & 0.814 & 1.00 & 1.00 & 68 \\
\hline 2 concrete & 1537 & 0.809 & 0.85 & 0.76 & 119 \\
\hline 3 autoclaved concrete & 295 & 0.207 & 3.00 & 3.96 & 68 \\
\hline 4 wood-like & 436 & 0.150 & & 2.68 & 278 \\
\hline 5 firebrick & 569 & 0.361 & & 2.05 & 83 \\
\hline 6 rockwool A-batts & 134 & 0.404 & & 8.72 & 4 \\
\hline 7 rockwool protection & 172 & 0.211 & & 6.79 & 22 \\
\hline 8 steel & 13152 & 31.125 & & 0.09 & 6 \\
\hline 9 non-existing & 436 & 1.500 & & 2.68 & 3 \\
\hline
\end{tabular}




\section{COMPUTER CALCULATIONS}

Computer calculations were carried out with the polyethylene design model (5) to derive the errors when conversion factors are used. All material properties were evaluated as a function of temperature (8), and the thermal response of the steel structures was calculated according to Bøhm \& Hadvig (11).

The greatest differences in maximum steel temperatures when either equation (1) is applied in the standard compartment or calculations are carried out in the real compartment are shown in Table 2. The table has been divided into two parts, eq. when the fire duration is shorter than the critical time (small fuel load), and when it is not (large fuel load). Apart from the compartment made of steel the greatest exror is smaller than 13 . However, if a critical steel temperature is desired as $500^{\circ} \mathrm{C} \pm 25^{\circ} \mathrm{C}$ then the error should not exceed $5 \%$.

For further details and in the cases with different homogeneous walls in the same compartment, non-homogeneous walls, and in the wood design case (3) the reader is referred to (8).

\section{CONCEPT OF NORMALIZED HEAT LOAD}

The normalized heat load (NHL) is calculated from

NHL $=\int_{0}^{\tau} \frac{q^{*}}{\sqrt{k \rho c}} d \tau$

where $q^{\prime \prime}$ is the net heat flux to the bounding walls and $\tau *$ is the duration of the fully developed fire.

Harmathy et al. (7) considered temperature-independent material properties which means that an effective value for the thermal inertia $\sqrt{\mathrm{koc}}$ must be evaluated, (12).

TABLE 2. Maximum errors in percentage of the value obtained from $\mathrm{k}_{-}$-method, with $\mathrm{k}_{\mathrm{f}}=1168 /(\sqrt{\mathrm{k} \rho \mathrm{c}}) 700^{\circ} \mathrm{C}$. First figure for unprotected structure and second figure for protected structure. 3 different fuel loads have been applied for every opening factor.

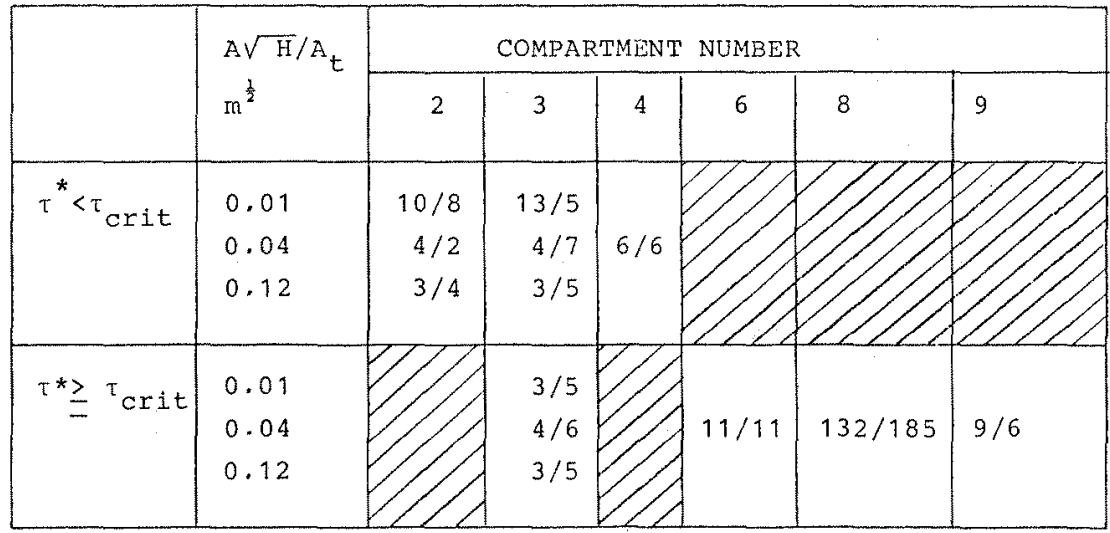


In Figure 1 is shown the normalized heat load in the standard compartment as a function of opening factor and fuel load. The thermal exposure is calculated in case of a polyethylene fire (5). The duration of the fully developed fire is also indicated in the figure.

Harmathy (13) and Paulsen (14) investigated the heat transfer in fire test furnaces. The normalized heat load on the test specimen increases when the furnace walls are made of a material with low thermal inertia. However, this variation in normalized heat load is small compared with the variation in real compartments, due to different fuel loads and opening factors. On the left side of the vertical scale in Figure 1 is shown the equivalent fire duration according to ISO 834 in a fire test furnace built of fire brick (material No. 5). The furnace is a typical gasfired European wall furnace with mean beam length $1.2 \mathrm{~m}$. The gas emissivity is calculated as a function of temperature and of the partial pressure of $\mathrm{CO}_{2}$ and $\mathrm{H}_{2} \mathrm{O}(\mathrm{p}$. $\mathrm{I}=0.3 \mathrm{~m} \mathrm{~atm})$. The measurement error between true gas gemperature and thermocouple signal is simulated, $(11,14)$. The thermal exposure in this furnace is slightly less than the exposure from a black gas.

\section{Equivalent Heat Load}

As an example 60 minutes fire duration according to Iso 834 is considered. From calculation or Figure 1 the normalized heat load is $46,400 \sqrt{\mathrm{s}} \mathrm{K}$ in the fire test furnace.

From the computer calculations with temperature dependent material properties it is possible (by interpolation) to find a fuel load so that the normalized heat load is equal to $46,400 \sqrt{\mathrm{s}} \mathrm{K}$. This is shown in Table 3 in the case of the standard compartment (No. 1) and in case of a compartment made of autoclaved concrete (No. 3 )

The table also shows the maximum steel temperature for the two previously mentioned structures (calculated according to $(5,11)$ ) and also the charring of a wooden structure, calculated according to Hadvig (15). In compartment No. 1 the maximum temperatures for the protected structure are $-16 / 43^{\circ} \mathrm{C}$ compared with the steel temperature in the fire endurance test. The charring depths are 1-4 mm greater than in the fire endurance test.

In compartment No. 3 the maximum steel temperatures for the protected structure are $+2 /+112^{\circ} \mathrm{C}$ compared with the steel temperature in the test furnace.

By using the normalized heat load concept as a principle of equivalent Fire duration the maximum steel temperature is thus getermined with an accuracy of $30 \%$ (compartment No. 3 and opening factor $0.30 \mathrm{~m}^{1 / 2}$ ). In most cases the accuracy is much better.

Table 3 also shows that the normalized heat load concept cannot be used for unprotected structures. These structures are sensitive to the gas temperature-time history, eg. maximum gas temperature and the incident flux.

For a specific structure an equivalent fire duration can at least in principle be calculated so that the structure obtains exactly the same critical temperature in the fire test furnace as in the real fire. The normalized heat load on the other hand establishes a relationship between the thermal exposure in different compartments without any knowledge of the structures being required. 


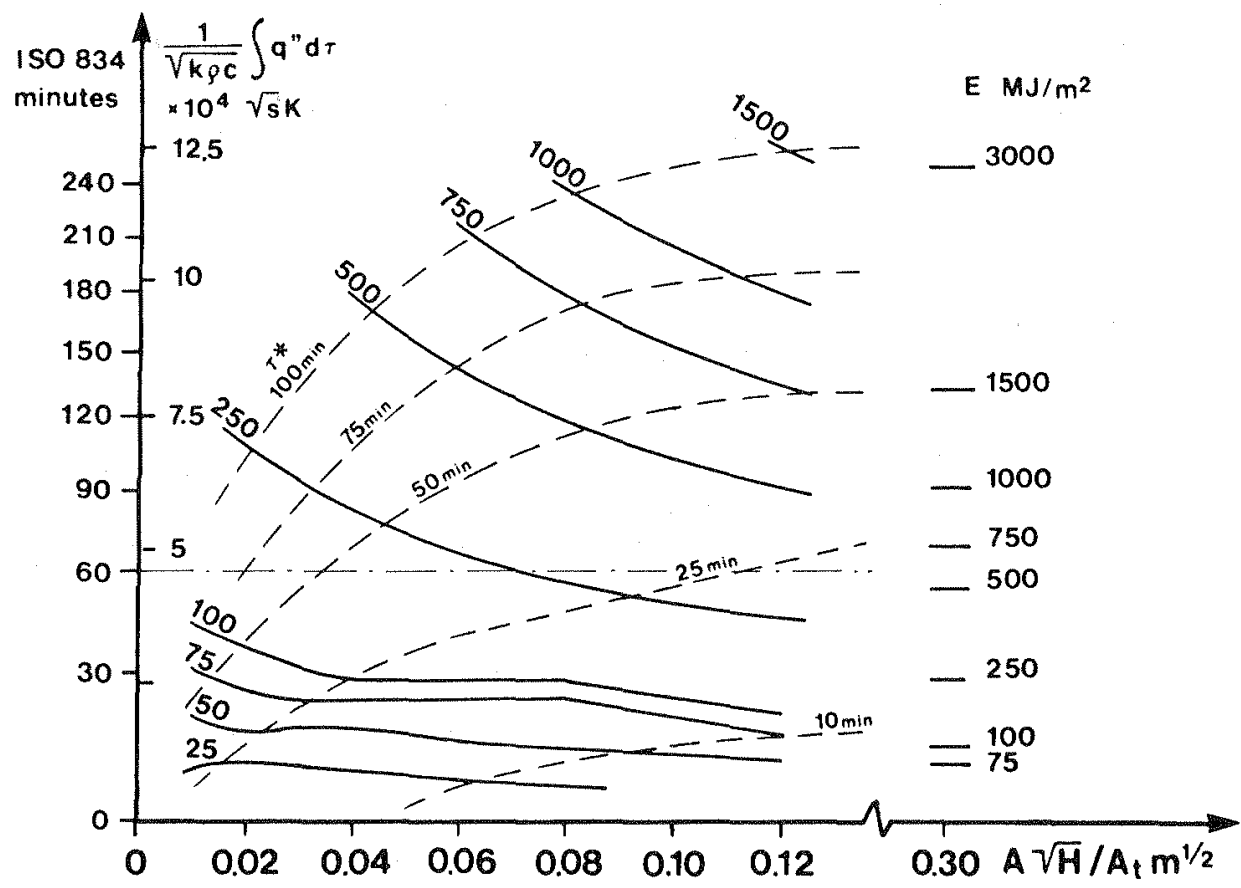

FIGURE 1. Normalized heat load in compartment No. 1 as a function of opening factor and fire load (-). Duration of fully developed fire indicated (--). Equivalent of fire duration according to ISO 834 shown on vertical scale. Normalized heat load in other compartments is estimated from:

$\mathrm{E}_{\text {No.1 }}=\mathrm{k}_{\mathrm{E}} \times \mathrm{E}_{\text {true }}$

$\mathrm{A} \sqrt{\mathrm{H}} / \mathrm{A}_{t}$ NO. $1=\mathrm{k}_{\mathrm{f}} \times \mathrm{A} \sqrt{\mathrm{H}} / \mathrm{A}_{t}$ true 
TABLE 3. Thermal exposure in the fire test furnace and compartments Nos. 1 and 3 for a normalized heat load of $46,400 \sqrt{\mathrm{s}} \mathrm{K}$

\begin{tabular}{|c|c|c|c|c|c|c|c|}
\hline & $\begin{array}{c}A \sqrt{\mathrm{H}} / A \\
\mathrm{~m}^{\frac{1}{2}}\end{array}$ & $\begin{array}{c}\mathrm{E} \\
\mathrm{MJ} / \mathrm{m}^{2}\end{array}$ & $\begin{array}{l}{ }^{T} g \max \\
{ }_{C}\end{array}$ & $\begin{array}{l}\int_{0}^{\tau *} H^{\prime \prime} d \tau \\
M J / m^{2}\end{array}$ & $\begin{array}{l}\text { Max temp } \\
\text { unprotected } \\
\text { steel } \\
{ }^{\circ} \mathrm{C}\end{array}$ & $\begin{array}{l}\text { Max temp } \\
\text { protected } \\
\text { steel } \\
\quad{ }^{\circ} \mathrm{C}\end{array}$ & $\begin{array}{c}\text { Charring } \\
\text { of wood } \\
\mathrm{mm}\end{array}$ \\
\hline $\begin{array}{l}1 \\
0 \\
0 \\
4 \\
4 \\
5 \\
4 \\
4 \\
4\end{array}$ & $\begin{array}{r}\text { ISO } 834 \\
(60 \mathrm{~min})\end{array}$ & - & 974 & 266 & 924 & 371 & 32 \\
\hline \multirow{7}{*}{ 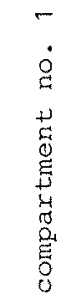 } & 0.01 & 130 & .686 & 200 & 679 & 355 & - \\
\hline & 0.02 & 152 & 861 & 235 & 851 & 365 & 36 \\
\hline & 0.04 & 190 & 1047 & 285 & 1041 & 368 & 34 \\
\hline & 0.06 & 228 & 1160 & 311 & 1152 & 380 & 35 \\
\hline & 0.08 & 264 & 1237 & 342 & 1231 & 384 & 33 \\
\hline & 0.12 & 335 & 1340 & 380 & 1334 & 395 & 34 \\
\hline & 0.30 & 655 & 1532 & 455 & 1530 & 414 & 34 \\
\hline \multirow{7}{*}{ 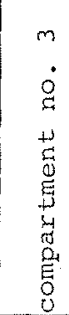 } & 0.01 & 49 & 1035 & 270 & 1030 & 373 & - \\
\hline & 0.02 & 72 & 1213 & 349 & 1207 & 398 & - \\
\hline & 0.04 & 116 & 1372 & 438 & 1369 & 425 & - \\
\hline & 0.06 & 159 & 1457 & 497 & 1455 & 446 & - \\
\hline & 0.08 & 204 & 1508 & 553 & 1507 & 462 & - \\
\hline & 0.12 & 289 & 1566 & 597 & 1564 & 468 & - \\
\hline & 0.30 & 650 & 1660 & 675 & 1660 & 483 & - \\
\hline
\end{tabular}

1 Interpolation

2 Thermocouple measurement error included

\section{CONCLUSIONS}

The thermal exposure in fully developed compartment fires can be evaluated in a standard compartment with thermal inertia $1168 \mathrm{~W} \sqrt{\mathrm{s}} / \mathrm{m}^{2} \mathrm{~K}$ if an equivalent fire load and an equivalent opening factor are used. The equivalent values are obtained as the true values in the real compartment multiplied with the conversion factor $k_{f}$.

The conversion factor is calculated as $1168 / \sqrt{\mathrm{kpc}} 0^{\circ}$, where $\sqrt{\mathrm{kpc}}$ is the thermal inertia in the real compartment, but the duration of the fire must be taken into consideration.

For homogeneous compartments the maximum error will be smaller than 13\%, except for compartment No. 8 made of steel. Often the error will be smaller. 
The normalized heat load concept, (7), can be used for well-protected structures as a measure of the destructive potential of a compartment fire. It can be used as a principle of equivalent fire duration for the transition from fire endurance tests to real fires with an estimated accuracy in maximum steel temperature of 30 .

\section{NOMENCLATURE}

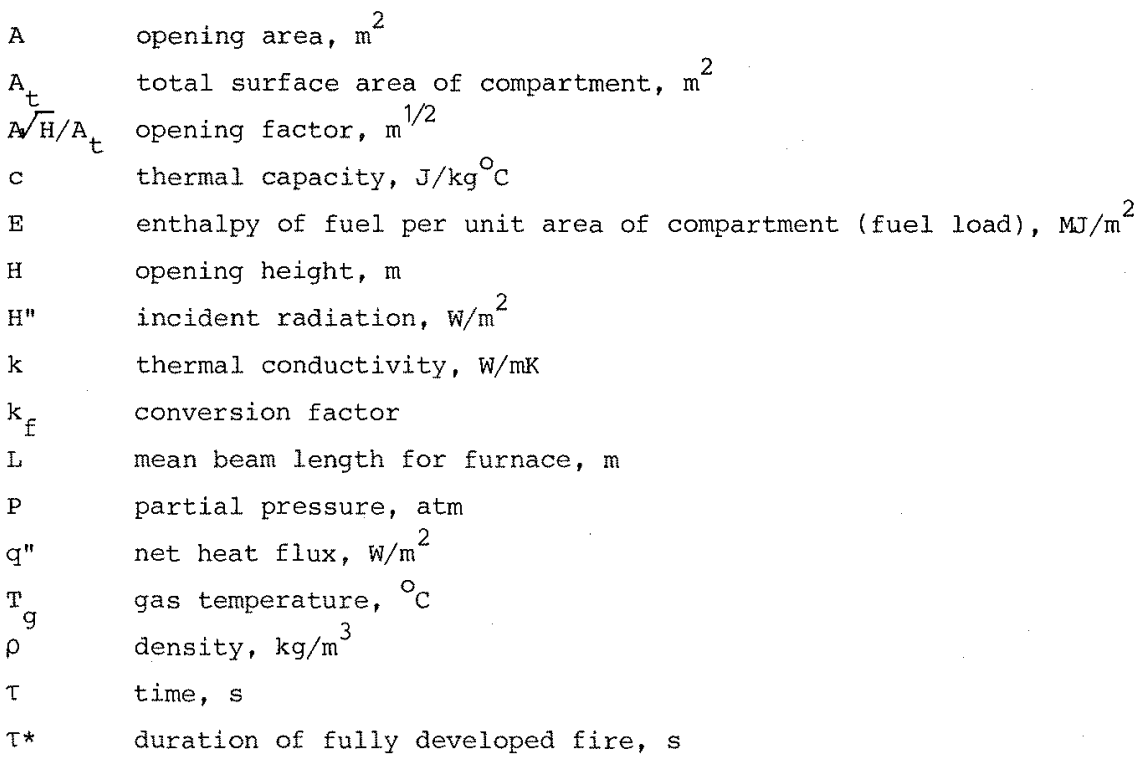

\section{REFERENCES}

1. Odeen, K.: "Theoretical Study of Fire Characteristics in Enclosed spaces," Bulletin 10. Royal Institute of Technology, stockholm, Sweden, 1963.

2. Kawagoe, K. and Sekine, T.: "Estimation for Fire Temperature-Time Curve in Rooms," BRI Occasional Report No. 11, Building Research Institute, Japan, 1963.

3. Magnusson, S.E. and Thelandersson, S.: "Temperature-Time Curves of Complete Process of Fire Development," Bulletin 16, Lund Institute of Technology, Sweden, 1970.

4. Pettersson, O., Magnusson, S.E., and Thor, J.: "Fire Engineering Design of steel structures," Publication 50, Swedish Institute of steel Construction, SBI, 1976.

5. Bøhm, B.: "Fully-Developed Polyethylene and Wood Compartment Fires with Application to Structural Design," Laboratory of Heating and Air-Conditioning, Technical university of Denmark, 1977.

6. Bøhm, B.: "Non-Uniform Compartment Fires. Report No. 1, Preliminary Investigation of Fully Developed Fires," Laboratory of Heating and AirConditioning, Technical University of Denmark, 1983. 
7. Harmathy, T.Z. and Mehaffey, J.R.: "Normalized Heat Load: A Key Parameter in Fire Safety Design," Fire and Materials, 6, 1, 1982.

8. Bøhm, B.: "On Thermal Inertia and Normalized Heat Load," Laboratory of Heating and Air Conditioning, Technical University of Denmark, 1984.

9. Harmathy, T.Z.: "Design of Fire Test Furnaces," Fire Technology, $\underline{5}, 2$, May 1969.

10. McCaffrey, B.J., Quintiere, J.G., and Harkleroad, M.F.: "Estimating Room Temperatures and the Likelihood of Flashover using Fire Test Data Correlations," Fire Technology, 17, 2, May 1981.

11. Bøhm, B. and Hadvig, S.: Fire Safety Journal, 5, 281-286, 1983.

12. Williams-Leir, G.: Fire and Materials, 8, 2, 1984.

13. Harmathy, T.z.: "The Fire Resistance Test and its Relation to Real-World Fires," Fire and Materials, $\underline{5}, 3,1981$.

14. Paulsen, O.: "On Heat Transfer in Fire Test Furnaces," Laboratory of Heating and Air Conditioning, Technical University of Denmark, 1975.

15. Hadvig, s.: Charring of wood in Building Fires, Technical University of Denmark, 1981 . 


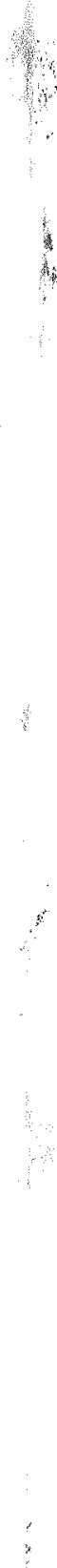

